\title{
Is Ultrafast or Abbreviated Breast MRI Ready for Prime Time?
}

\author{
Ritse M. Mann ${ }^{1} \cdot$ Jan C. M. van Zelst ${ }^{1} \cdot$ Suzan Vreemann ${ }^{1} \cdot$ Roel D. M. Mus ${ }^{1}$ \\ Published online: 21 January 2019 \\ (C) The Author(s) 2019
}

\begin{abstract}
Purpose of Review Breast MRI has been recognized as the most sensitive modality for breast cancer screening. Its use is, however, restricted due to the high costs of the MRI scan itself, the limited availability of MRI scanners and the long reading times. In this review, the use of shorter MRI protocols for screening is discussed.

Recent Findings Shortened scan protocols have been proposed to reduce both the actual patient handling time and the time to evaluate the scan. So far, these "abbreviated" scan protocols have shown similar sensitivity and only marginally lower specificity as the common scan protocols, while largely reducing scan time and time required for evaluation. To retain the dynamic information, ultrafast dynamic breast MRI was introduced, capturing the inflow of contrast in a lesion. This comes for free in terms of scan time. The diagnostic information from this dynamic evaluation is even stronger than the conventional curve types and can be exceptionally helpful in the evaluation of small lesions. Since abbreviated and ultrafast MRIs are not mutually exclusive, both techniques can be combined, yielding a screening protocol with a scan time below 5 min. However, only very few studies evaluated these protocols in a true screening setting, and the number of detected cancers is likewise very low. Summary Abbreviated protocols with ultrafast MRI allow shortening of breast MRI for screening while retaining excellent sensitivity and specificity. Prospective study data are however limited and must be further substantiated.
\end{abstract}

Keywords Breast cancer $\cdot$ Screening $\cdot$ Abbreviated breast MRI $\cdot$ Ultrafast breast MRI

\section{Introduction}

The incidence of breast cancer is increasing worldwide. The risk of developing breast cancer can be up to $15 \%$, depending on the country [1]. Current treatment options are more simple and better tolerated if the cancers are detected at an early stage. In addition, cancers that are detected early have a better disease-free survival and overall survival than advanced staged cancers [2•]. Screening for breast cancer is important to allow early detection of cancer before the cancer is clinically found. Screening modality for breast cancer is mainly mammography worldwide. Some Asian countries prefer breast ultrasound as the primary screening tool due to the relatively small and dense breasts of women in these countries.

This article is part of the Topical Collection on Breast Cancer Imaging and Screening

Ritse M. Mann

ritse.mann@ radboudumc.nl

1 Department of Radiology, Radboud University Medical Centre, P.O.Box 9100, 6500 HB Nijmegen, The Netherlands
The mammographic screening programs have been highly successful in reducing breast cancer-related mortality, with reported breast cancer-related mortality reductions of up to $58 \%$ for women who actually received screening mammography [3]. Nevertheless, mammography still fails to detect breast cancers at an early stage in up to $30 \%$ of women, who eventually develop distant metastasis and may die from the disease. Mammography functions especially poor in women who are at high risk for developing breast cancer, with a reported sensitivity below $50 \%[4,5]$. After the discovery of contrast-enhanced breast MRI in the mid-eighties [6,7], it was soon recognized that breast MRI had a considerable advantage over mammography for early breast cancer detection with its higher sensitivity. Studies focusing on screening for breast cancer in women with high risk revealed that there is higher incidence of breast cancer in these high-risk women, and as a result, fewer patients are needed to be enrolled in these trials in order to yield significant results. The results of these initial breast MRI screening trials in different countries were unequivocal, despite the variation in patient populations; the sensitivity of breast MRI is roughly double that of mammography [4-5, 8-10]. In addition, breast MRI triples the additional yield of breast US as a supplementary screening test for women at increased risk [11]. Finally, the use of breast 
MRI as a screening tool induces a stage shift in these women and a substantially lower risk for distant metastasis and death (0-16\% and $0-7 \%$, respectively), when compared to historical cohorts (27-30\% and 17-25\%, respectively) [12, 13].

Based upon the initial MRI screening studies, the American Cancer Society published its recommendation in 2007 where women with a life-time risk of 20-25\% or higher are recommended to have annual breast MRI in addition to screening mammography. This recommendation was subsequently adopted by the European Society for Breast Imaging (EUSOBI) [14•, 15]. Despite the presence of these guidelines, many national organizations do not adhere to these recommendations due to issues with costs. For women with genetic mutation, screening MRI is cost-effective [16]; however, there are still controversies for performing screening MRI on women at moderate or low risk. The addition of MRI to screening mammogram in the moderate to low-risk population was felt not to be cost-effectiveness [17].

Meanwhile, further evaluation of MRI as a screening tool in populations at lower risk is ongoing. In a recently published study with very liberal inclusion criteria, the supplemental cancer detection using breast MRI in women at average risk, with a negative screening mammogram, was 15.5 per thousand in the first round, which reduced to 6.9 per thousand in incidence rounds (nearly all only detected with MRI), fairly equal to the mammographic detection rates in Europe, and therefore once again showing the potential of breast MRI to induce a stage shift in breast cancer detection [18•]. Further prospective randomized trials in women with extremely dense breasts and women with an increased risk based upon family history alone are ongoing [19, 20]. Despite the very likely highly positive results of these trials in terms of early cancer detection and reduction of interval cancers, it can be anticipated that cost-effectiveness analysis will once again show that breast MRI in these populations is, in general, not affordable, thus limiting the use of an otherwise highly effective screening tool.

For further implementation of breast MRI as a screening tool, it is thus mandatory to reduce the costs of the examination itself, which can be most easily achieved by increasing the throughput of patients in the MRI scanner.

\section{Abbreviated Breast MRI}

The abbreviated MRI is a shortened version of a full protocol or standard breast MRI exam, currently performed for screening breast cancer. The concept of the abbreviated protocol is to reduce the length of the acquisition and interpretation time of a screening breast MRI exam to a minimum. Most researchers focus on reducing the acquisition time of a standard breast MRI exam which have been reported to be up to $45 \mathrm{~min}$. The criteria for defining an exam abbreviated or having a limit on the exam time for an MRI protocol to be called abbreviated is not yet determined. For the purpose of this paper, we will assume that an abbreviated breast MRI protocol will have a scan time of less than $5 \mathrm{~min}$. Since patient handling times vary between 5 to $10 \mathrm{~min}$, this allows approximately four and six breast MRI exams to be performed per hour on a scanner.

Most of the currently used breast MRI protocols consists of at least a dynamic contrast-enhanced series [7 $\mathrm{min}]$, a T2weighted series, and possibly a diffusion weighted series lasting between 15 and $20 \mathrm{~min}$. Longer protocols that are for clinical care, without research sequences or non-FDA approved sequences, not needed or encouraged [15, 21]. Publications on abbreviated breast MRI to date usually involve acquiring a full breast MRI protocol, with analyzed subsets of sequences interpreted in a blinded fashion and separate from the full protocol. There are no published studies that used only abbreviated MRI for screening currently.

In 2014, Kuhl and colleagues were the first to report the feasibility of the simplest form of abbreviated MRI [22••]. Their version of abbreviated protocol consisted of an unenhanced T1-weighted sequence and first contrastenhanced T1-weighted sequence, subtraction images with a single maximum intensity projections (MIP) [22••]. This protocol took 3 min of scan time: $60 \mathrm{~s}$ delay from the start of IV contrast injection to allow the contrast agent to flow into potential lesions followed by each T1-weighted acquisitions lasting approximately $60 \mathrm{~s}$. Interpretation was performed using MIP from the post-contrast subtraction images (Fig. 1), and therefore is extremely fast (reported to be less than $2 \mathrm{~s}$ ), allowing quick dismissal of normal cases. With this approach, the reported overall sensitivity was $91 \%$ with MIP only and $100 \%$ with the complete subtraction series. The specificity was $94.3 \%$, with a negative predictive value of $99.8 \%$. The main advantage of using the full diagnostic protocol over abbreviated protocol was the ability to better characterize BIRADS 3 or probable benign lesions. These breast imagingreporting and data system (BI-RADS) 3 lesions constituted $9 \%$ of lesions detected on abbreviated MRI. While the entire study included 606 screens, it only detected 11 cancers; therefore, solid conclusions about sensitivity and specificity cannot be drawn. In a study by Mango et al. evaluating 100 breast MRI examinations of patients with biopsy proven breast cancers, the reported sensitivity for interpreting the MIP images alone was also substantially lower than when evaluating the actual subtraction images (84-96\%, vs 93-98\%, over different readers)[23]. It must be stressed that dismissing studies as normal based upon the MIP images alone requires very good quality MIP images without motion artifacts. Subsequent studies evaluating different variations of abbreviated protocols are listed in Table 1. Of note is that several abbreviated protocols do not conform to the definition of a true abbreviated protocol given above, as the scan time is far longer than would be acceptable for high-throughput screening. 
Fig. 1 Maximum intensity projection of subtracted postcontrast acquisition, clearly showing a multifocal invasive lobular cancer in the left breast

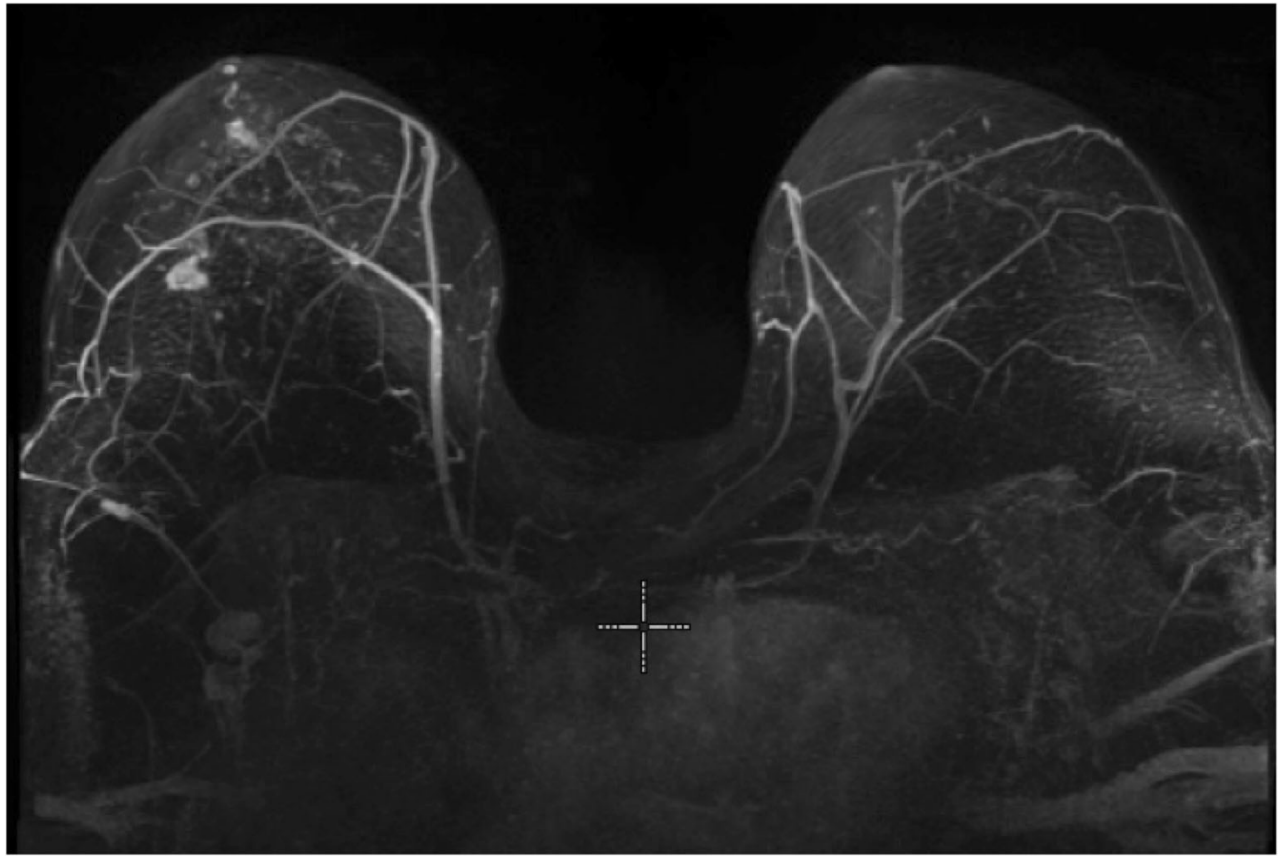

Table 1 Studies comparing abbreviated protocols to full diagnostic protocols: effects on sensitivity and specificity.

\begin{tabular}{|c|c|c|c|c|c|c|}
\hline Author (year) & $\begin{array}{l}\text { Abbreviated protocol } \\
\text { (duration) }\end{array}$ & $\begin{array}{l}\text { Number of cancers/ } \\
\text { total cases }\end{array}$ & $\begin{array}{l}\text { Sensitivity } \\
\text { Abbreviated } \\
\text { Protocol }\end{array}$ & $\begin{array}{l}\text { Specificity } \\
\text { Abbreviated } \\
\text { Protocol }\end{array}$ & $\begin{array}{l}\text { Sensitivity } \\
\text { Full diagnostic } \\
\text { protocol }\end{array}$ & $\begin{array}{l}\text { Specificity } \\
\text { Full diagnostic } \\
\text { protocol }\end{array}$ \\
\hline $\begin{array}{l}\text { Kuhl } 2014 \\
\quad[22]\end{array}$ & $\mathrm{T} 1$ pre- and post-contrast ( $3 \mathrm{~min})$ & $\begin{array}{l}\text { 11/606 (screening } \\
\text { population) }\end{array}$ & $100 \%$ & $94.3 \%$ & $100 \%$ & $93.4 \%$ \\
\hline $\begin{array}{l}\text { Mango } 2015 \\
\quad[23]\end{array}$ & $\begin{array}{l}\text { Sag T1 pre- and post-contrast } \\
\quad(10-15 \mathrm{~min})^{*}\end{array}$ & 100 (cancers only) & $93-98 \%$ & NA & $95-98 \%$ & NA \\
\hline $\begin{array}{l}\text { Grimm } 2015^{\mathrm{a}} \\
\quad[24]\end{array}$ & $\begin{array}{l}\text { T2 FS, T1 pre- and post-contrast } \\
(21 \mathrm{~min})^{*}\end{array}$ & $12 / 48$ (enriched) & $86 \%$ & $52 \%$ & $95 \%$ & $52 \%$ \\
\hline$\underset{[24]}{\operatorname{Grimm}} 2015^{\mathrm{a}}$ & $\begin{array}{l}\text { T2 FS, T1 pre- and post-contrast + } \\
\text { second post-contrast } \\
(23 \mathrm{~min})^{*}\end{array}$ & $12 / 48$ (enriched) & $89 \%$ & $45 \%$ & $95 \%$ & $52 \%$ \\
\hline $\begin{array}{l}\text { Harvey } 2016 \\
\quad[25]\end{array}$ & $\begin{array}{l}\text { T1 pre- and post contrast } \\
(4.4 \mathrm{~min})\end{array}$ & $\begin{array}{l}\text { 7/568 (screening } \\
\text { population) }\end{array}$ & 100 & $94 \%$ & 100 & $96 \%$ \\
\hline $\begin{array}{l}\text { Heacock } \\
\qquad 2016^{\mathrm{a}}[26]\end{array}$ & $\begin{array}{l}\text { T1 pre- and post-contrast } \\
(7 \mathrm{~min})\end{array}$ & 107 (cancers only) & $97.8 \%$ & NA & $99.4 \%$ & NA \\
\hline $\begin{array}{l}\text { Heacock } \\
2016^{\mathrm{a}}[26]\end{array}$ & $\begin{array}{l}\text { T2 FS, T1 pre- and post-contrast } \\
(12 \mathrm{~min})\end{array}$ & 107 (cancers only) & $99.4 \%$ & NA & $99.4 \%$ & NA \\
\hline $\begin{array}{l}\text { Moschetta } \\
2016[27]\end{array}$ & $\begin{array}{l}\text { T2 STIR, T2, T1 pre- and post-contrast } \\
(10 \mathrm{~min})\end{array}$ & $\begin{array}{l}75 / 470 \text { (clinical } \\
\text { population) }\end{array}$ & $89 \%$ & $91 \%$ & $92 \%$ & $92 \%$ \\
\hline $\begin{array}{l}\text { Chen } 2017 \\
\text { [28] }\end{array}$ & T1 pre- and post-contrast (3 min) & $\begin{array}{l}16 / 478 \text { (dense breast } \\
\text { screening) }\end{array}$ & $93.8 \%$ & $88.3 \%$ & $100 \%$ & $94.6 \%$ \\
\hline $\begin{array}{l}\text { Petrillo } 2017 \\
\text { [29] }\end{array}$ & $\mathrm{T} 1$ pre- and post-contrast ( $3 \mathrm{~min})$ & $\begin{array}{l}207 / 508 \text { (clinical } \\
\text { population) }\end{array}$ & $99.5 \%$ & $75.4 \%$ & $99.5 \%$ & $77.1 \%$ \\
\hline $\begin{array}{l}\text { Chen } 2017^{\mathrm{a}} \\
{\left[30^{\bullet}\right]}\end{array}$ & $\mathrm{T} 1$ pre- and post-contrast ( $3 \mathrm{~min})$ & $\begin{array}{l}\text { 14/356 (dense breast } \\
\text { screening) }\end{array}$ & $92.9 \%$ & $86.5 \%$ & $100 \%$ & $96.8 \%$ \\
\hline $\begin{array}{l}\text { Chen } 2017^{\mathrm{a}} \\
{\left[30^{\bullet}\right]}\end{array}$ & $\begin{array}{l}\text { T1 pre- and post-contrast }+ \text { DWI } \\
(6 \mathrm{~min})\end{array}$ & $\begin{array}{l}\text { 14/356 (dense breast } \\
\text { screening) }\end{array}$ & $100 \%$ & $95 \%$ & $100 \%$ & $96.8 \%$ \\
\hline $\begin{array}{l}\text { Romeo } 2017 \\
{[31]}\end{array}$ & $\mathrm{T} 1$ pre- and $3 *$ post-contrast $(7 \mathrm{~min})$ & 110/180 (lesions only) & $99 \%$ & $93 \%$ & $97 \%$ & $95 \%$ \\
\hline $\begin{array}{l}\text { Panigrahi } \\
2017 \\
{[32]}\end{array}$ & $\mathrm{T} 1$ pre- and post-contrast ( $3 \mathrm{~min})$ & $\begin{array}{l}\text { 11/678 (high-risk } \\
\text { screening) }\end{array}$ & $81.8 \%$ & $97.2 \%$ & $81.8 \%$ & $97.4 \%$ \\
\hline
\end{tabular}

* Scan time reported includes patient positioning

${ }^{a}$ reported two different abbreviated protocols in one study 
Most authors reported that the sensitivity of abbreviated MRI is equal to the sensitivity of a full diagnostic protocol. However, results on specificity are more heterogeneous. While several authors did not report any deviation, many authors report a small to substantial decrease in specificity when evaluating abbreviated breast MRI [25, 27, 28, 30•, 31]. This is in line with the initial study of Kuhl et al. and seems to be related to the evaluation of more difficult "probably benign" lesions and relatively small lesions. Heacock et al. reported that lesion conspicuity in malignant breast lesions could be increased by adding a T2-weighted sequence to the abbreviated protocol [26], whereas Chen et al. improved specificity substantially by adding a diffusion weighted sequence [30॰]. Several authors only reduce the number of post-contrast T1weighted acquisitions to more than one, thus still enabling dynamic evaluation of breast lesions in the abbreviated protocol, which is likewise aimed at preserving the specificity as it does not seem to have effect on sensitivity. Recently, Strahle et al. tried to define an optimal abbreviated protocol by assessing the diagnostic value of each of the sequences. They obtained the best results by reducing the full protocol to a shortened, but still dynamic T1-weighted series, interleaved with a normal T2 sequence for a total acquisition time of $7.5 \mathrm{~min}$, underlining the added discriminatory value of dynamics and to lesser extent T2 [33]. It should be noted that their full protocol however did not include DWI. In conclusion, it is evident that abbreviated MRI allows shortening of the full diagnostic breast MRI protocol, without a significant reduction in sensitivity. Effects on specificity are mainly limited to patients with lesions of low suspicion for malignancy and can be improved by either preserving dynamic evaluation, or adding T2 and DWI. However, whether the extension in acquisition time required for improved lesion classification is economically viable in a situation where most scans are completely negative (i.e., in screening, especially non-highrisk) remains debatable.

\section{Ultrafast Breast MRI}

Ultrafast breast MRI is developed to capture the inflow of contrast in breast lesions and hence enable dynamic analysis of contrast wash-in rather than contrast wash-out. The technique builds largely on earlier attempts to analyze the pharmacokinetic characteristics of breast cancer vasculature, which was shown to allow good separation between benign and malignant breast lesions [34, 35]. The main difference between these techniques, however, is that ultrafast breast MRI is performed with a spatial resolution that enables morphological assessment of eventual breast lesions as it meets the international standards for diagnostic breast MRI, and can therefore also be used for lesion detection. Like abbreviated MRI, the term "ultrafast" is not clearly defined and sometimes used for MRI techniques that are not exceptionally fast. In this paper, ultrafast breast MRI is defined as T1-weighted imaging with a temporal resolution below $6 \mathrm{~s}$, and a spatial resolution of at least $1 \times 1 \times 2.5 \mathrm{~mm}$.

Herrmann et al. in 2011 was the first to publish, on the approach of $\mathrm{k}$-space filling, allowed construction of highresolution breast MRI acquisitions at a temporal resolution of $5.7 \mathrm{~s}$ [36]. The commercial name of this sequence is timeresolved angiography with stochastic trajectories (TWIST). Hence, TWIST has become almost a synonym for ultrafast breast MRI. Le et al. and Saranathan et al. subsequently showed that similar results were also possible using fatsaturated and Dixon techniques. However, these sequences are computationally heavy and therefore require long reconstruction times [37, 38].

In 2014, we proposed the use of ultrafast breast MRI alone as a new screening technique for breast cancer, based upon a study of 199 abnormalities where the wash-in characteristics obtained with TWIST were compared to the wash-out characteristics from the same lesions obtained from regular T1weighted series. The ultrafast protocol obtained $20 \mathrm{~T} 1-$ weighted acquisition volumes at a temporal resolution of $4.3 \mathrm{~s}$ each, for a total duration of $102 \mathrm{~s}$. Therefore, this technique is faster than any of the abbreviated protocols discussed previously in this article. This approach shows that the maximum slope (MS), a heuristic dynamic parameter obtained from the TWIST images largely outperformed the conventional curve types (area under the curve 0.81 vs 0.69 ), while still allowing imaging at diagnostic spatial resolution. MS can be assessed in a similar way as the curve types, where a steep slope is indicative of malignancy; a shallow slope of a likely benign lesion and an intermediate curve is indeterminate [39••]. In further studies, it was subsequently shown that also the time to enhancement relative to aortic enhancement (TTE) is a highly discriminative and very reproducible parameter for breast lesion characterization [40]. In simple words, lesions that enhance within $10 \mathrm{~s}$ after the aorta are likely malignant; lesions that enhance between 10 and $15 \mathrm{~s}$ after the aorta are indeterminate, and lesions that enhance more than $15 \mathrm{~s}$ after the aorta are likely benign. As ultrafast breast MRI allows the generation of a series of MIP images (one for each postcontrast time point acquired), it is possible to evaluate these dynamic MIPS as a movie of contrast inflow. Based upon the above, the first enhancing lesion is usually the one that deserves most attention. In patients with cancer, you may observe a "lightbulb" effect, as you see the cancer enhancing in an otherwise completely black breast (Fig. 2). This effect is also very valuable for the evaluation of breasts with nodular background enhancement, to differentiate true lesions from focal areas of adenosis [41]. Another approach is the assessment of the time between arterial phase and venous phase in breast lesions. When arterial supply is observed, the lesion has a very high likelihood of being malignant. The level of 

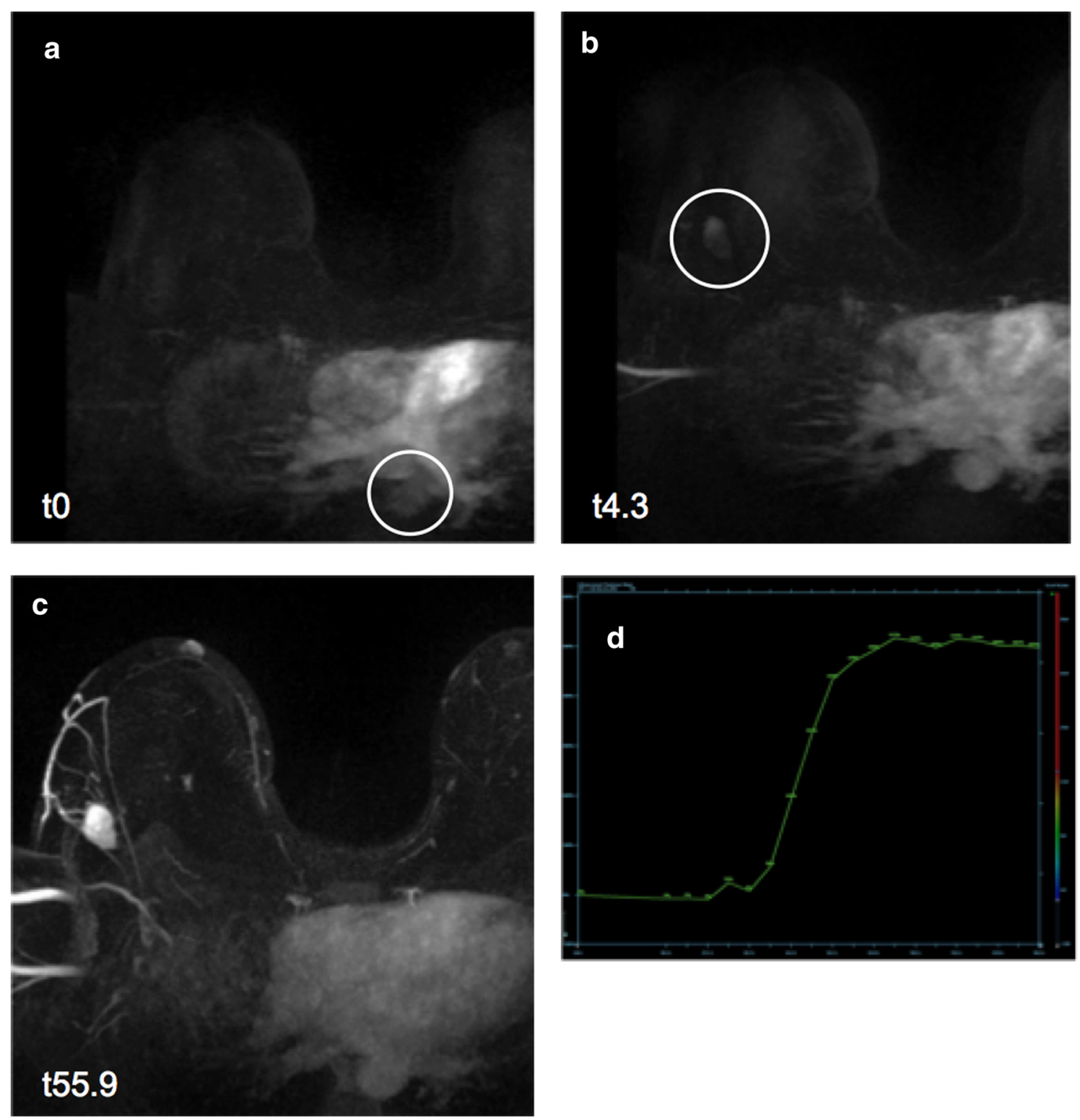

Fig. 2 Maximum intensity projections from an ultrafast dynamic series with a temporal resolution of $4.3 \mathrm{~s}$. TTE is relative to the enhancement of the descending aorta, the first volume that shows this vessel is designated t0 (a). In $\mathbf{b}$, the first volume where the lesion is visible is shown, the very early enhancement (only $4.3 \mathrm{~s}$ after the aorta) make it very likely that this

suspicion for malignancy is further increased when the time from arterial phase to venous drainage is shortened, a parameter that is highly related to the TTE described above [42]. It is recommended to evaluate the MIP images generated from the last time point obtained before evaluating the other sequences. If this MIP is of good quality and is negative for suspicious lesions, then evaluation of the other phases or sequences is not necessary. This observation is consistent with observations reported on MIP reading proposed by Kuhl et al. and Mango et al. Of note is that the excellent discriminating capacities of MS and TTE are also valid for computer-aided diagnosis [43], and remain valid over various types of breast cancer, including

lesion is malignant. In later time points, morphology becomes clear and can be easily appreciated (c). In $\mathbf{d}$, the time versus signal intensity curve for the inflow period is presented. The very steep upslope is indicative of malignancy

invasive lobular cancers and ductal carcinoma in situ [44]. It is still essential to realize that, even though with TWIST, a spatial resolution is obtained of $1 \times 1 \times 2.5 \mathrm{~mm}$; this is still lower than in most high-resolution T1-weighted protocols where voxels usually are below $1 \mathrm{~mm}$ isotropic. Consequently, multiplane reconstruction is somewhat limited, and therefore, morphological evaluation is not as good as with conventional protocols in all directions. However, recent studies employing compressed sensing with iterative reconstruction rather than view sharing allow a substantial further reduction of the spatial resolution, down to $0.8 \times 0.8 \times 1.6 \mathrm{~mm}$, in the same timeframe $[45,46]$. 
Whether ultrafast MRI alone is good enough for breast screening remains to be evaluated, as most published studies to date have mainly focused on lesion classification. Van Zelst et al., however, showed in a reader study with TWIST only versus a full diagnostic protocol on 85 biopsied screen-detected lesions, including 31 malignancies, obtained from over 3000 screening examinations, with 115 normal cases. The average sensitivity of TWIST only evaluation was $84 \%$, compared to $86 \%$ for the full diagnostic protocol, without statistical significance. However, the relative low sensitivities show the difficulty of the comprised case set consisting of only screening cases. Typically, the average specificity of TWIST only reading was, at $81 \%$, significantly higher than with the full diagnostic protocol at $77 \%$, while the average area under the curve for the two reading modes was virtually identical $[47 \bullet \bullet]$.

\section{Hybrid Imaging}

It is important to realize that the definitions of abbreviated and ultrafast MRI are not mutually exclusive. In fact, ultrafast MRI alone is a form of an abbreviated protocol with a very short acquisition time (less than $2 \mathrm{~min}$ ). However, for the performance of ultrafast breast MRI as a stand-alone technique, specific sequences are required that are not uniformly available. With classic, and far more commonly available, keyhole techniques (i.e., turboFLASH, eThrive, etc.), it is, unfortunately, not possible to obtain the required temporal resolution at a diagnostically acceptable spatial resolution. Nevertheless, even in the most basic form of an abbreviated protocol, the period of contrast inflow must be observed. Kuhl et al. solved this by simply waiting $60 \mathrm{~s}$ before acquiring the post-contrast acquisition. Obviously, ultrafast acquisitions (even of lower spatial resolution) can be inserted in this waiting period without any penalty in overall scanning time. This still allows vary fast evaluation of the entire protocol by evaluating the MIP image and high-resolution subtraction series, but in the presence of lesions, substantial additional dynamic information is present for lesion classification (it should be noted that when the last post-contrast scan is negative, it is not needed to evaluate all the previous phases). The superior performance of wash-in characteristics from ultrafast imaging compared to standard wash-out evaluation truly makes late phase acquisitions obsolete and enables a huge shortening of the protocol without losing any information. Whether or not addition of $\mathrm{T} 2$ or DWI is beneficial in the screening, setting remains to be seen.

\section{Conclusions}

Breast MRI as a screening tool is limited by the high cost of the MRI examination itself. To enable more widespread use of this highly sensitive screening technique, it is important to reduce the price of the exam and scanning time. The most practical approach to that is shortening the acquisition or scan time, allowing for an increase in patient's throughput and potential leading to a reduction in price of each exam. This will likely lead to increased patients' acceptance and expansion of the MRI screening population to those with intermediate risk for the development of breast cancer, those with a positive family history without hereditary genetic mutations, and those women with extremely dense breasts. Abbreviated protocols, particularly those employing (also) ultrafast sequences, may offer the best combination. Even though recent studies have investigated such protocols, the actual number of screen detected breast cancers remains very low and questions the value of abbreviated and ultrafast MRI as a screening technique. Based on the current results, the sensitivity of abbreviated MRI is not significantly different from that of a full diagnostic protocol but better than mammography, tomosynthesis, or ultrasound. This already underlines its potential value for supplemental evaluation of women with very dense breasts, even when it is still somewhat unsure whether it can completely replace the full diagnostic protocol in women currently already screened with MRI. The specificity of abbreviated breast MRI is lower than that of a full diagnostic protocol. This may lead to higher recall rate and additional evaluations. The incorporation of ultrafast breast MRI sequences to the abbreviated protocol may help improve this. In conclusion, ultrafast and/or abbreviated MRI will most likely become the standard screening MRI technique of the future.

Funding Information This work was supported by the Netherlands Organization for Health Research and Development (Grant Agreement No. 90514524).

\section{Compliance with Ethical Standards}

Conflict of Interest Ritse Mann reports grants and non-financial support from Siemens Healthineers, grants from Bayer Healthcare, grants from Medtronic, grants from Screenpont Medical, grants from Seno Medical, grants from Mircima, and grants from Identification Solutions, Inc., outside the submitted work. Roel Mus, Suzan Vreeman, and Jan van Zelst declare no conflicts of interest relevant to this manuscript.

Human and Animal Rights and Informed Consent This article does not contain any studies with human or animal subjects performed by any of the authors. 
Open AccessThis article is distributed under the terms of the Creative Commons Attribution 4.0 International License (http:// creativecommons.org/licenses/by/4.0/), which permits unrestricted use, distribution, and reproduction in any medium, provided you give appropriate credit to the original author(s) and the source, provide a link to the Creative Commons license, and indicate if changes were made.

Publisher's Note Springer Nature remains neutral with regard to jurisdictional claims in published maps and institutional affiliations.

\section{References}

Papers of particular interest, published recently, have been highlighted as:

- Of importance

•- Of major importance

1. van der Waal D, Verbeek AL, den Heeten GJ, Ripping TM, TjanHeijnen VC, Broeders MJ. Breast cancer diagnosis and death in the Netherlands: a changing burden. Eur J Pub Health. 2015;25(2): 320-4. https://doi.org/10.1093/eurpub/cku088.

2. Saadatmand S, Bretveld R, Siesling S, Tilanus-Linthorst MM. Influence of tumour stage at breast cancer detection on survival in modern times: population based study in 173,797 patients. BMJ. 2015;351:h4901. https://doi.org/10.1136/bmj.h4901 This study shows that also in the era of modern therapy earlier detection of breast cancer leads to improved survival.

3. Paap E, Verbeek AL, Botterweck AA, van Doorne-Nagtegaal HJ, Imhof-Tas M, de Koning HJ, et al. Breast cancer screening halves the risk of breast cancer death: a case-referent study. Breast. 2014;23(4):439-44. https://doi.org/10.1016/j.breast.2014.03.002.

4. Kriege M, Brekelmans CT, Boetes C, Besnard PE, Zonderland HM, Obdeijn IM, et al. Magnetic resonance imaging screening study group. Efficacy of MRI and mammography for breast-cancer screening in women with a familial or genetic predisposition. N Engl J Med. 2004;351(5):427-37.

5. Leach MO, Boggis CR, Dixon AK, Easton DF, Eeles RA, Evans DG, et al. Screening with magnetic resonance imaging and mammography of a UK population at high familial risk of breast cancer: a prospective multicentre cohort study (MARIBS). Lancet. 2005;365(9473):1769-78 Erratum in: Lancet 2005 May 28Jun 3;365(9474):1848.

6. Heywang SH, Hahn D, Schmidt H, Krischke I, Eiermann W, Bassermann R, et al. MR imaging of the breast using gadoliniumDTPA. J Comput Assist Tomogr. 1986;10(2):199-204.

7. Kaiser WA, Zeitler E. MR imaging of the breast: fast imaging sequences with and without Gd-DTPA. Preliminary observations. Radiology. 1989;170(3 Pt 1):681-6.

8. Warner E, Plewes DB, Hill KA, Causer PA, Zubovits JT, Jong RA, et al. Surveillance of BRCA1 and BRCA2 mutation carriers with magnetic resonance imaging, ultrasound, mammography, and clinical breast examination. JAMA. 2004;292(11):1317-25.

9. Sardanelli F, Podo F, Santoro F, Manoukian S, Bergonzi S, Trecate G, et al. High breast cancer risk Italian 1 (HIBCRIT-1) study. Multicenter surveillance of women at high genetic breast cancer risk using mammography, ultrasonography, and contrast-enhanced magnetic resonance imaging (the high breast cancer risk italian 1 study): final results. Investig Radiol. 2011;46(2):94-105. https:// doi.org/10.1097/RLI.0b013e3181f3fcdf.

10. Kuhl C, Weigel S, Schrading S, Arand B, Bieling H, König R, et al. Prospective multicenter cohort study to refine management recommendations for women at elevated familial risk of breast cancer: the
EVA trial. J Clin Oncol. 2010;28(9):1450-7. https://doi.org/10. 1200/JCO.2009.23.0839.

11. Berg WA, Zhang Z, Lehrer D, Jong RA, Pisano ED, Barr RG, et al. Detection of breast cancer with addition of annual screening ultrasound or a single screening MRI to mammography in women with elevated breast cancer risk. JAMA. 2012;307(13):1394-404. https://doi.org/10.1001/jama.2012.388.

12. Rijnsburger AJ, Obdeijn IM, Kaas R, Tilanus-Linthorst MM, Boetes C, Loo CE, et al. BRCA1-associated breast cancers present differently from BRCA2-associated and familial cases: long-term follow-up of the Dutch MRISC Screening Study. J Clin Oncol. 2010;28(36):5265-73. https://doi.org/10.1200/JCO.2009.27.2294.

13. Brekelmans CT, Tilanus-Linthorst MM, Seynaeve C, vd Ouweland A, Menke-Pluymers MB, Bartels CC, et al. Tumour characteristics, survival and prognostic factors of hereditary breast cancer from BRCA2-, BRCA1- and non-BRCA1/2 families as compared to sporadic breast cancer cases. Eur J Cancer. 2007;43(5):867-76.

14. Saslow D, Boetes C, Burke W, Harms S, Leach MO, Lehman CD, et al. American Cancer Society guidelines for breast screening with MRI as an adjunct to mammography. CA Cancer J Clin. 2007;57(2):75-89 Erratum in: CA Cancer J Clin. 2007 MayJun;57(3):185. This manuscript provides the current standard recommendations for selection of women to be screened with MRI.

15. Mann RM, Kuhl CK, Kinkel K, Boetes C. Breast MRI: guidelines from the European Society of Breast Imaging. Eur Radiol. 2008;18(7):1307-18. https://doi.org/10.1007/s00330-008-0863-7.

16. Taneja C, Edelsberg J, Weycker D, Guo A, Oster G, Weinreb J. Cost effectiveness of breast cancer screening with contrast-enhanced MRI in high-risk women. J Am Coll Radiol. 2009;6(3):171-9. https://doi.org/10.1016/j.jacr.2008.10.003.

17. Griebsch I, Brown J, Boggis C, Dixon A, Dixon M, Easton D, et al. UK Magnetic Resonance Imaging in Breast Screening (MARIBS) Study Group. Cost-effectiveness of screening with contrast enhanced magnetic resonance imaging vs X-ray mammography of women at a high familial risk of breast cancer. Br J Cancer. 2006;95(7):801-10.

18. Kuhl CK, Strobel K, Bieling H, Leutner C, Schild HH, Schrading S. Supplemental breast MR imaging screening of women with average risk of breast cancer. Radiology. 2017;283(2):361-70. https:// doi.org/10.1148/radiol.2016161444 This study shows that also in women at average risk, MRI contribution to early cancer detection is high.

19. Emaus MJ, Bakker MF, Peeters PH, Loo CE, Mann RM, de Jong $\mathrm{MD}$, et al. MR imaging as an additional screening modality for the detection of breast cancer in women aged 50-75 years with extremely dense breasts: the DENSE trial study design. Radiology. 2015;277(2):527-37. https://doi.org/10.1148/radiol.2015141827.

20. Saadatmand S, Rutgers EJ, Tollenaar RA, Zonderland HM, Ausems MG, Keymeulen KB, et al. Breast density as indicator for the use of mammography or MRI to screen women with familial risk for breast cancer (FaMRIsc): a multicentre randomized controlled trial. BMC Cancer. 2012;12:440. https://doi.org/10. 1186/1471-2407-12-440.

21. Sardanelli F, Boetes C, Borisch B, Decker T, Federico M, Gilbert FJ, et al. Magnetic resonance imaging of the breast: recommendations from the EUSOMA working group. Eur J Cancer. 2010;46(8): 1296-316. https://doi.org/10.1016/j.ejca.2010.02.015.

22.• Kuhl CK, Schrading S, Strobel K, Schild HH, Hilgers RD, Bieling HB. Abbreviated breast magnetic resonance imaging (MRI): first postcontrast subtracted images and maximum-intensity projectiona novel approach to breast cancer screening with MRI. J Clin Oncol. 2014;32(22):2304-10. https://doi.org/10.1200/JCO.2013. 52.5386 This study launches the idea of abbreviated breast MRI. It shows that virtually all cancers can be detected by 
only evaluating 1 pre- and 1 postcontrast acquisition, and the subtractions of these acquisitions.

23. Mango VL, Morris EA, David Dershaw D, Abramson A, Fry C, Moskowitz CS, et al. Abbreviated protocol for breast MRI: are multiple sequences needed for cancer detection? Eur J Radiol. 2015;84(1):65-70. https://doi.org/10.1016/j.ejrad.2014.10.004.

24. Grimm LJ, Soo MS, Yoon S, Kim C, Ghate SV, Johnson KS. Abbreviated screening protocol for breast MRI: a feasibility study. Acad Radiol. 2015;22(9):1157-62. https://doi.org/10.1016/j.acra. 2015.06.004

25. Harvey SC, Di Carlo PA, Lee B, Obadina E, Sippo D, Mullen L. An Abbreviated protocol for high-risk screening breast MRI saves time and resources. J Am Coll Radiol. 2016;13(11S):R74-80. https:// doi.org/10.1016/j.jacr.2016.09.031.

26. Heacock L, Melsaether AN, Heller SL, Gao Y, Pysarenko KM, Babb JS, et al. Evaluation of a known breast cancer using an abbreviated breast MRI protocol: correlation of imaging characteristics and pathology with lesion detection and conspicuity. Eur $\mathrm{J}$ Radiol. 2016;85(4):815-23. https://doi.org/10.1016/j.ejrad.2016. 01.005 .

27. Moschetta M, Telegrafo M, Rella L, Stabile Ianora AA, Angelelli G. Abbreviated combined MR protocol: a new faster strategy for characterizing breast lesions. Clin Breast Cancer. 2016;16(3):20711. https://doi.org/10.1016/j.clbc.2016.02.008.

28. Chen SQ, Huang M, Shen YY, Liu CL, Xu CX. Application of Abbreviated protocol of magnetic resonance imaging for breast cancer screening in dense breast tissue. Acad Radiol. 2017;24(3): 316-20. https://doi.org/10.1016/j.acra.2016.10.003.

29. Petrillo A, Fusco R, Sansone M, Cerbone M, Filice S, Porto A, et al. Abbreviated breast dynamic contrast-enhanced MR imaging for lesion detection and characterization: the experience of an Italian oncologic center. Breast Cancer Res Treat. 2017;164(2):401-10. https://doi.org/10.1007/s10549-017-4264-y.

30. Chen SQ, Huang M, Shen YY, Liu CL, Abbreviated XCX. MRI protocols for detecting breast cancer in women with dense breasts. Korean J Radiol. 2017;18(3):470-5. https://doi.org/10.3348/kjr. 2017.18.3.470 This is the first study on breast MRI screening in women with extremely dense breasts as risk factor.

31. Romeo V, Cuocolo R, Liuzzi R, Riccardi A, Accurso A, Acquaviva A, et al. Preliminary results of a simplified breast MRI protocol to characterize breast lesions: comparison with a full diagnostic protocol and a review of the current literature. Acad Radiol. 2017;24: 1387-94. https://doi.org/10.1016/j.acra.2017.04.011.

32. Panigrahi B, Mullen L, Falomo E, Panigrahi B, Harvey S. An Abbreviated protocol for high-risk screening breast magnetic resonance imaging: impact on performance metrics and BI-RADS assessment. Acad Radiol. 2017;24:1132-8. https://doi.org/10.1016/j. acra.2017.03.014

33. Strahle DA, Pathak DR, Sierra A, Saha S, Strahle C, Devisetty K. Systematic development of an abbreviated protocol for screening breast magnetic resonance imaging. Breast Cancer Res Treat. 2017;162(2):283-95. https://doi.org/10.1007/s10549-017-4112-0.

34. Tofts PS, Berkowitz B, Schnall MD. Quantitative analysis of dynamic Gd-DTPA enhancement in breast tumors using a permeability model. Magn Reson Med. 1995;33(4):564-8.

35. Veltman J, Stoutjesdijk M, Mann R, Huisman HJ, Barentsz JO, Blickman JG, et al. Contrast-enhanced magnetic resonance imaging of the breast: the value of pharmacokinetic parameters derived from fast dynamic imaging during initial enhancement in classifying lesions. Eur Radiol. 2008;18(6):1123-33. https://doi.org/10.1007/ s00330-008-0870-8.

36. Herrmann KH, Baltzer PA, Dietzel M, Krumbein I, Geppert C, Kaiser WA, et al. Resolving arterial phase and temporal enhancement characteristics in DCE MRM at high spatial resolution with TWIST acquisition. J Magn Reson Imaging. 2011;34(4): 973-82. https://doi.org/10.1002/jmri.22689.

37. Le Y, Kipfer H, Majidi S, Holz S, Dale B, Geppert C, et al. Application of time-resolved angiography with stochastic trajectories (TWIST)-Dixon in dynamic contrast-enhanced (DCE) breast MRI. J Magn Reson Imaging. 2013;38(5):1033-42. https://doi.org/ 10.1002/jmri.24062.

38. Saranathan M, Rettmann DW, Hargreaves BA, Lipson JA, Daniel BL. Variable spatiotemporal resolution three-dimensional Dixon sequence for rapid dynamic contrast-enhanced breast MRI. J Magn Reson Imaging. 2014;40(6):1392-9. https://doi.org/10. 1002/jmri.24490.

39.• Mann RM, Mus RD, van Zelst J, Geppert C, Karssemeijer N, Platel B. A novel approach to contrast-enhanced breast magnetic resonance imaging for screening: high-resolution ultrafast dynamic imaging. Investig Radiol. 2014;49(9):579-85. https://doi.org/10. 1097/RLI.0000000000000057 This study launched the idea of ultrafast breast MRI for breast cancer screening using combined high spatial, high temporal resolution acquisitions during contrast inflow.

40. Mus RD, Borelli C, Bult P, Weiland E, Karssemeijer N, Barentsz JO, et al. Time to enhancement derived from ultrafast breast MRI as a novel parameter to discriminate benign from malignant breast lesions. Eur J Radiol. 2017;89:90-6. https://doi.org/10.1016/j. ejrad.2017.01.020.

41. Pineda FD, Medved M, Wang S, Fan X, Schacht DV, Sennett C, et al. Ultrafast bilateral DCE-MRI of the breast with conventional Fourier sampling: Preliminary Evaluation of Semi-quantitative Analysis. Acad Radiol. 2016;23(9):1137-44. https://doi.org/10. 1016/j.acra.2016.04.008.

42. Onishi N, Kataoka M, Kanao S, Sagawa H, Iima M, Nickel MD, et al. Ultrafast dynamic contrast-enhanced MRI of the breast using compressed sensing: breast cancer diagnosis based on separate visualization of breast arteries and veins. J Magn Reson Imaging. 2017;47:97-104. https://doi.org/10.1002/jmri.25747.

43. Platel B, Mus R, Welte T, Karssemeijer N, Mann R. Automated characterization of breast lesions imaged with an ultrafast DCEMR protocol. IEEE Trans Med Imaging. 2014;33(2):225-32. https://doi.org/10.1109/TMI.2013.2281984.

44. Dalmış MU, Gubern-Mérida A, Vreemann S, Karssemeijer N, Mann R, Platel B. A computer-aided diagnosis system for breast DCE-MRI at high spatiotemporal resolution. Med Phys. 2016;43(1):84-94. https://doi.org/10.1118/1.4937787.

45. Benkert T, Block KT, Heller S, Moccaldi M, Sodickson DK, Kim $\mathrm{SG}$, et al. Comprehensive dynamic contrast-enhanced 3D magnetic resonance imaging of the breast with fat/water separation and high spatiotemporal resolution using radial sampling, compressed sensing, and parallel imaging. Investig Radiol. 2017;52:583-9. https:// doi.org/10.1097/RLI.0000000000000375.

46. Vreemann S, Rodriguez-Ruiz A, Nickel D, Heacock L, Appelman L, van Zelst J, et al. Compressed sensing for breast MRI: resolving the trade-off between spatial and temporal resolution. Investig Radiol. 2017;52:574-82. https://doi.org/10.1097/RLI. 0000000000000384 .

47.• Van Zelst J, Gubern-Merida A, Vreemann S, Veltman J, Dorrius M, Loo C, et al. Multireader study on the diagnostic accuracy of ultrafast breast magnetic resonance imaging for breast cancer screening. Investig Radiol. 2018;53(10):579-86. https://doi.org/10.1097/RLI. 000000000000494 This study shows that reading only ultrafast breast MRI for screening yields an equal sensitivity as reading a full protocol, and specificity even increases. 